\title{
A ESSÊNCIA AUTÔNOMA DA OBRA DE ARTE NA ESTÉTICA DE KARL MORITZ
}

Mario Spezzapria*

\begin{abstract}
Resumo: No ensaio Sobre a imitação formadora do belo (1788) Moritz denuncia a insuficiência do recurso ao prazer como critério distintivo para explicar a origem do belo, e propõe considerar este sentimento como o efeito secundário de algo mais originário: a estrutura autotélica da obra de arte. As reflexões de Moritz movem-se a partir de uma crítica ao conceito de útil, considerado como atributo típico de um objeto que não tem em si seu próprio fim, ao contrário do que acontece no objeto belo, cuja beleza exclui qualquer referência externa. Moritz interroga sobre a imanência do valor estético nas obras de arte, e sobre a correlação entre perfeição e finalidade interna. $\mathrm{O}$ objeto artístico, desligado de qualquer referência a fins externos e de cada intencionalidade externa adquire, por assim dizer, uma maior objetividade. Ao mesmo tempo, porém, a reflexão moritziana opera uma deslocação de atenção da natureza estrutural do objeto artístico pela atividade criadora do artista. $\mathrm{O}$ objeto belo não é apenas imitado-observado, mas imitado-criado. O sumo prazer sensual para o belo na obra de arte deriva da criação perfeita. A estética de Moritz pode ser, portanto considerada como o esforço de pensar a coexistência de duas instâncias antitéticas: por um lado, a tendência a insistir sobre uma maior "concretização objetiva" da obra de arte, além da intencionalidade subjetiva do artista que a cria; por outro lado, o relevo dado à atividade criadora, e não à mera contemplação. Considerada do ponto de vista do artista, a autonomia consiste no fato de que o artista inventa cada vez uma regra de composição daquela totalidade que é a obra de arte. A "conciliação" dessas duas instâncias antitéticas permite que a obra de arte para Moritz seja um objeto ao mesmo tempo mais determinado em si mesmo (se considerado enquanto independente da atribuição intencional de valores externos), e menos determinado por si mesmo (enquanto seu valor essencial consiste no estímulo a recriar novamente, ou seja, ele move o espectador a assumir a responsabilidade de se tornar por sua vez artista, recriando o belo).
\end{abstract}

Palavras-chave: autonomia da obra de arte, autotelia, gênio, criação artística

Nesta apresentação pretende-se expor brevemente algumas questões sobre a essência da "obra de arte", que surgem da maneira como Karl Philipp Moritz, romancista e teórico da arte, alemão da secunda metade do século XVIII, a considera dotada de uma própria irredutível autonomia. Consideraremos suas obras mais relevantes pela teoria estética, o Ensaio para unificar todas as belas artes e belas letras sob o conceito do perfeito e acabado em $\mathrm{si}^{1}$, de 1785, e Sobre a imitação formadora do belo², de 1788, nas quais se encontra um

\footnotetext{
* Doutorando do Programa de Pós-Graduação em Filosofia da Universidade de São Paulo. Bolsista da Capes. E-mail: mariospezzapria@yahoo.it.

${ }^{1}$ MORITZ, K. P. Versuch einer Vereinigung aller schönen Künste und Wissenschaften unter dem Begriff des in sich selbst Vollendeten. In: . Werke in zwei Bände. Bd. 2. Popularphilosophie, Reisen, Ästhetische Theorie. HOLLMER, H.; MEIER, A. (Hrsg.). Frankfurt am Main: Deutscher Klassiker Verlag, 1997. p. 943-949. Tradução para português: MORITZ, K. P. Ensaio para unificar todas as belas artes e belas letras sob o conceito do perfeito e acabado em si.
} 
contínuo questionamento da relação entre os conceitos de autonomia e de autotelia. O tema da autonomia declina-se no pensamento de Moritz seguindo pelo menos duas direções (embora se trate de dois aspectos do mesmo problema): em primeiro lugar, o nosso autor sustenta a tese da autonomia da obra de arte; secundariamente, da autonomia do agir criador do artista.

\section{A autonomia da obra de arte}

Moritz define seu conceito de belo a partir da oposição às teorias contemporâneas que consideravam o prazer dado pela fruição de uma obra de arte um elemento decisivo. No Ensaio para unificar todas as belas artes e belas letras sob o conceito do perfeito e acabado em si critica a ideia de que seja possível utilizar a categoria do prazer como critério distintivo entre o que é belo e o que é útil, já que os dois são ambos fontes de prazer. Sensações prazerosas surgem seja em presença de objetos uteis (cuja utilidade provoca prazer), seja na frente de objetos belos. Estas considerações eram dirigidas contra o filósofo berlinense Moises Mendelssohn, que nas Considerações sobre as fontes e relações entre as belas artes e as ciências ${ }^{3}$ (1757) sustentava a opinião de que o fim da arte fosse a capacidade de causar prazer. Moritz, em vez disso, acha que tanto o belo como o útil produzem prazer e, por isso, que não se pode recorrer a tal principio como critério distintivo entre beleza e utilidade. Ademais, ele sustenta que, além do prazer, o mesmo principio de utilidade não pode ser de ajuda quando falamos de arte e de beleza, em consideração ao tipo de finalidade em jogo no âmbito estético. Mantendo sempre o belo como conceito na base do próprio argumentar, Moritz lhe confere caráter fundamental graças à aproximação com a ideia humanística de totalidade (e com o conceito de origem baumgartiana de Vollkommenheit, "acabamento") porque o belo, encontrando-se completamente expresso numa obra de arte, é uma totalidade e, enquanto tal, tem o seu fim em si, em si se acaba e conclui, diferentemente do que ocorre com o útil:

No meramente útil eu me contento não tanto com o próprio objeto quanto com a representação da comodidade e do conforto, cujo uso do objeto confere a mim ou a outra pessoa. Eu me ponho por assim dizer no centro, ao qual relaciono todas as partes do objeto, isto é, considero o objeto apenas como meio - contanto que minha perfeição seja desse modo promovida - do qual eu mesmo sou o fim. O objeto meramente útil, portanto, não é em si mesmo nem um todo nem algo perfeito e acabado, mas somente se torna um quando alcança o seu fim ou se completa em mim. Na contemplação do belo, porém, eu coloco de volta no próprio objeto o fim que estava em mim: eu não o considero como algo completo em mim, mas nele mesmo, formando, portanto, um todo em si, e proporcionando-me

Tradução de José Feres Sabino, in: SABINO, J. F. Ensaios de Karl Philipp Moritz: linguagem, arte, filosofia. 2009. 145p. Dissertação (Mestrado em Filosofia). FFLCH, Universidade de São Paulo, São Paulo. 2009, p. 108-114

${ }^{2}$ MORITZ, K. P. Über die bildende Nachahmung des Schönen. Stuttgart: G. J. Göschen'sche Verlagshandlung, 1888.

${ }^{3}$ MENDELSSOHN, M. Über der Hauptgrundsätze der schönen Künste und Wissenschaften. In: . Asthetische Schriften. POLLOCK, A. (Hrsg.). Hamburg: Felix Meiner, 2006. p. 188-215. 
prazer em razão de si mesmo, e por isso o objeto belo se refere menos a mim do que eu a ele. $^{4}$

Segundo o nosso autor, a utilidade dum objeto, de fato, não se encontra nele mesmo, mas exteriormente a ele, pelo menos sob dois aspectos: em primeiro lugar, na medida em que a qualidade de utilidade não faz parte das suas características essenciais e constitutivas e depende de várias circunstâncias (a mesma coisa podendo ser percebida em algumas ocasiões como útil, em outras como inútil); e em segundo lugar, porque um objeto é sempre útil ou inútil para um sujeito que o define como tal, instrumentalmente ao uso que intende fazer dele. No belo, por sua vez, há sempre uma finalidade interna operando:

[O belo] não tem seu fim fora dele, e não existe em função da perfeição de outra coisa, mas em função da própria perfeição interna. ${ }^{5}$

Esta referência à autotelia (isto é, à finalidade interna de um objeto) é fundamental na teoria estética moritziana, segundo a qual a beleza de uma obra-prima perfeita se explica pelo fato de que o objeto "obra de arte" é completamente "acabado": todas as partes que o compõem (formas, linhas, cores) estão em harmonia e realizam um equilíbrio perfeito de coerência interna. Assim, em Determinação do fim de uma teoria das belas-artes (1789), ao longo da argumentação sobre a possibilidade de um "sistema" das artes, Moritz afirma:

... para considerar qualquer bela obra de arte como um inteiro subsistente para se, é necessário encontrar na própria obra de arte o ponto de vista por meio do qual todas as coisas singulares se presentam na própria relação necessária com o inteiro, e fica claro que na obra de arte não há nada supérfluo, nem faltante. Ensinar a encontrar este ponto de vista para o belo em todos os casos, seria portanto a tarefa de uma teoria completa das belas artes. $^{6}$

Trata-se de uma teoria com uma forte implicação estruturalista: tudo acontece entorno do objeto artístico, e das suas estruturas internas, e a beleza não é uma qualidade dada exteriormente, nem subjetivamente. A obra da arte "bela" apresenta-se essencialmente e fundamentalmente autônoma e autotélica, e, enquanto tal, pode ser autonomamente usufruída, ela deixa transitar transparentemente o seu significado mais íntimo, ou seja, a sua essência; ela "fala por si mesma". Consequentemente, a sua contemplação, ou melhor, a contemplação daquelas partes que compõem a totalidade que ela é, implica de

\footnotetext{
${ }^{4}$ MORITZ, K. P. Ensaio para unificar todas as belas artes e belas letras sob o conceito do perfeito e acabado em si. Tradução de José Feres Sabino, in: SABINO, J. F. Ensaios de Karl Philipp Moritz: linguagem, arte, filosofia. 2009. 145p. Dissertação (Mestrado em Filosofia). FFLCH, Universidade de São Paulo, São Paulo. 2009, p. 108.

${ }^{5}$ Ibidem, p. 109.

${ }^{6}$ MORITZ K. P. Bestimmung des Zwecks einer Theorie des schönen Künste. In: Poetik. SCHRIMPF, H. J. (Hrsg.). Berlin: De Gruyter, 2011, p. 122 [minha tradução]. . Schriften zur Ästhetik und
} 
qualquer maneira um esquecer-nos de nós mesmos, como se o sujeito se dissolvesse num grau supremo de prazer puro desinteressado:

Enquanto o belo atrai totalmente nossa contemplação, ele a faz desviar um instante de nós mesmos e parecer que nos perdemos no objeto belo; e esse perder-se, esse esquecimento de nós mesmos, é o grau mais alto de prazer puro e desinteressado que o belo nos proporciona. $^{7}$

Considerada sob esse aspecto, as implicações da autonomia da obra de arte não concerniam então apenas a sua legibilidade (tornando problemática a possibilidade mesma das práticas hermenêuticas e exegéticas da crítica e da história da arte), mas se alargavam para envolver a natureza mesma da subjetividade do "utilizador-espectador". O deslocamento de atenção da relação entre o objeto artístico e o espectador em favor da relação entre obra da arte e artista-criador (o ator principal, capaz de colher a verdade mais profunda e a essência da arte) implicava de fato um afastamento da importância do espectador.

\section{A autonomia do artista criador}

Em Sobre a imitação formadora do belo, voltando a refletir sobre os conceitos-chave de beleza e utilidade já utilizados na Ensaio de 1785, Moritz aprofunda ulteriormente a questão de autonomia da obra de arte. O nosso autor distingue claramente entre Tatkraft (energia criativa do artista criador) e Vorstellungraft (força de imaginação do espectador e do amante da arte). É verdade que permanece um sentido no qual também o espectador ou o amante da arte, excluindo um conhecimento racional da obra de arte, participa na criação, embora não sendo ele mesmo o artista, por meio duma fruição intuitiva (Empfindungsfähigkeit), como imitação do processo criativo, mas trata-se sempre de um sucedâneo, um nível de participação inferior, e o homem aspirará, em vez disso, sempre movido pela força da beleza, a tornar-se ele mesmo artista:

Todos os inteiros belos que nascem das mãos do artista formador [des bildenden Künstlers] são, portanto, marcas pequenas do belo supremo no grande inteiro da natureza. Esta continua criando mediatamente, através da mão formadora do artista, o que não faz parte imediatamente do seu grande projeto. Assim, aquele em cujo ser a natureza imprimiu o sentido da sua força criadora e em cujos olhos e alma a medida do belo, não se contenta de contemplá-la; deve imitá-la, emulá-la, espiá-la na sua oficina segreda, e formar e criar, como ela faz - com a chama ardente no peito. ${ }^{8}$

${ }^{7}$ Ibidem, p. 110.

${ }^{8}$ MORITZ, K. P. Über die bildende Nachahmung des Schönen. Stuttgart: G. J. Göschen'sche Verlagshandlung, 1888, p. 14. [minha tradução]. 
Essa enfatização do papel do artista-criador ocorre em concomitância com uma reelaboração do conceito de imitação (Nachahmung). Isso permite a passagem de um fazer artístico meramente mimético a um agir poiético. Trata-se de considerar a imitação não como atividade passiva (adequação, espelhamento) mas ativa; sobretudo, considerando-a não tanto enquanto representação de objetos, mas em analogia ao processo criativo mesmo da Natureza; ela é assim um imitar que tem a mesma força operante (Tatkraft). Um artista é então em primeiro lugar gênio, o qual está em condições de produzir formas por imitação da lei criativa natural. Com isso, Moritz traça um paralelismo do ânimo humano com o próprio processo criativo-formativo da Natureza, uma vez que para ele está claro que a obra de arte, como a natureza, deve ser pensada não como produto, mas como produtiva. É a ideia mesma de forma que liga mundo natural e artístico não como uma coisa fixa, dada de maneira definitiva, mas como formação (Bildung). Assim, graças às analogias nos procedimentos formativos entre formas vivas e belas, a arte é considerada como expressão, em formas concretas, de regras. As obras de arte são uma coisa viva, tanto quanto a natureza. Ambas, procedendo segundo regras, produzem formas vivas e, nesse sentido, a natureza é o modelo estrutural de qualquer forma artística.

Este conceito "dinâmico" da essência das obras de arte nos conduz a fazer uma última consideração sobre a característica de "acabamento" da obra de arte. A afirmação de um forte "caráter objetivo" da obra de arte, desvinculada dos juízos subjetivos externos (do espectador) e de uma forte intencionalidade subjetiva (atribuição de finalidade) por parte do artista, não implica uma conspiração do objeto "obra de arte" como algo fixo, delimitado e definido. Acentuando a autotelia do objeto artístico, a reflexão moritziana, com efeito, tende a se apresentar como pensamento das relações e das proporcionalidades presentes na obra de arte. Assim, ao questionar sobre a origem e natureza do belo, segundo Moritz a atenção deve ser colocada não no objeto entendido como "representado", imitação especular de uma realidade externa à representação, mas no próprio espelhamento. Moritz recorre amplamente à metáfora do espelho, para sugerir que o importante não está na imagem que ele restitui (que a bem ver é sempre mais ou menos deformada), quando no permanecer de relações prospécticas, as quais conferimos sentido graças à individuação de um ponto de vista. Dito em outros termos, o "acabamento" da obra de arte não deve ser pensado em relação a uma forma-Gestalt, mas a uma forma-Bildung, onde a forma formante é dinâmica e "viva".

Mas voltando a considerar a atividade criativa do artista, em que sentido se pode falar de uma imitação que não seja uma mera reprodução de formas já dadas, mas uma "criação"? Este tema é amplamente desenvolvido em Sobre a imitação criadora do belo, nos termos de uma análise detalhada das dinâmicas psicológicas das forças que convergem na Tatkraft. Ao redor dessa questão convergem o conceito de autonomia da obra de arte e aquilo de autonomia do agir criador. É o próprio conceito de perfeição (Vollkommenheit), que em Moritz se traduz na ideia de obra de arte "acabada em si mesma" (vollendet), que permite entender a relação entre os conceitos de autonomia do agir criativo e a autotelia da obra de arte. Com efeito, a estética de Moritz pode ser considerada como o esforço de pensar a coexistência (não privada de problema e ambiguidade) de duas instâncias antitéticas: por um lado, a tendência a insistir sobre uma maior "concretização objetiva" da obra de arte, além da intencionalidade subjetiva do artista que a cria (sem que esta "objetividade", como vimos, signifique entender o objeto artístico como uma forma fixa, determinada); por outro lado, o relevo dado à atividade criadora, e não à mera contemplação. Considerada do ponto de vista do artista, sua autonomia consiste no fato de que ele inventa cada vez uma regra de composição daquela totalidade "acabada" que é a obra de arte. Ele "imita" a perfeição da estrutura dela. A "conciliação" (ou a "sobreposição") dessas duas instâncias antitéticas permite que a obra de arte para Moritz seja um objeto ao mesmo tempo mais determinado em si mesmo (se considerado enquanto independente da atribuição intencional de valores externos), e menos determinado por si mesmo (em um duplo sentido: enquanto sua 
beleza depende das relações internas, e enquanto seu valor essencial consistir no estímulo a recriar, ou seja, ele incita o espectador a assumir a responsabilidade de se tornar artista, recriando/reproduzindo as regras de perfeição da beleza em novos objetos originais).

\section{BIBLIOGRAFIA}

MENDELSSOHN, M. Über der Hauptgrundsätze der schönen Künste und Wissenschaften. In:

Ästhetische Schriften. POLLOCK, A. (Hrsg.). Hamburg: Meiner, 2006. p. 188-215.

MORITZ K. P. Bestimmung des Zwecks einer Theorie des schönen Künste. In: Schriften zur Ästhetik und Poetik. SCHRIMPF, H. J. (Hrsg.). Berlin: De Gruyter, 2011, p. 122.

MORITZ, K. P. Über die bildende Nachahmung des Schönen. Stuttgart: G. J. Göschen'sche Verlagshandlung, 1888.

MORITZ, K. P. Versuch einer Vereinigung aller schönen Künste und Wissenschaften unter dem Begriff des in sich selbst Vollendeten. In: . Werke in zwei Bände. Bd. 2. Popularphilosophie, Reisen, Ästhetische Theorie. HOLLMER, H.; MEIER, A. (Hrsg.). Frankfurt am Main: Deutscher Klassiker Verlag, 1997. p. 943-949. Tradução para português:

MORITZ, K. P. Ensaio para unificar todas as belas artes e belas letras sob o conceito do perfeito e acabado em si. Tradução de José Feres Sabino, in: SABINO, J. F. Ensaios de Karl Philipp Moritz: linguagem, arte, filosofia. 2009. 145p. Dissertação (Mestrado em Filosofia). FFLCH, Universidade de São Paulo, São Paulo. 2009, p. 108114. 